\title{
Biomedical health practitioners' views regarding the practices and health care delivery methods of the African indigenous health practitioners' in Mpumalanga province, South Africa
}

\author{
TinyikoEnneth Nkhwashu RN,PhD ${ }^{1}$, Fhumulani Mavis Mulaudzi RN,D Litt et \\ $\mathrm{Phil}^{2}$ and Mogomme Alpheus Masoga $\mathrm{PhD}^{3}$ \\ Department of Nursing, SefakoMakgatho Health Sciences University, South Africa \\ Department of Nursing, University of Pretoria, South Africa \\ Social of Human and Social Sciences, University of Venda, South Africa
}

\begin{abstract}
Approval of the Traditional Health practitioners Act 22 of 2007 causedgreat concern among biomedical health practitioners because it was believed that African indigenous practitioners use African medicine that is detrimental to the health of the community. Theywere treated as illiterate and unscientific,and believed to be practicingin unclean conditions. It was expected that the establishment of the legislation wouldpromote collaboration between the biomedical and African indigenous health practitioners, however the formerare still reluctant to integrate with the latter. The aim of this article is to explore the views of the latter regarding the practices and healthcare delivery methods of their African counterparts in Mpumalanga Province, South Africa. A purposive sampling method was used to select 10 knowledgeable participants on the phenomenon, using structured in-depth interviews. Whilst they believedAfrican indigenous health practitioners should be empowered in order to change their practices and healthcare delivery methods it is also recommended that the biomedical ones conduct meetings, workshops, health education and awareness for the benefit of the indigenous practitioners and those in need of their service.
\end{abstract}

Keywords: African indigenous health practitioners/Biomedical;healthcare delivery methods; Mpumalanga province; Views

\section{Introduction}

The marginalisation of African indigenous health practices will remain an impediment to healing and fighting diseases on the continent if integration ofbiomedical practicesis not improved. The formerpredate the latterby centuries or more, but areperceivedas being carried out by illiterate, unscientific practitioners in unclean conditions and with the use of witchcraft and traditional medicine that is strong and unmeasured [1] ${ }^{1}$.

For centuriesthe two types of health practitioner were operating in parallel but in secret, withmore than $80 \%$ of the population consulting the African indigenous ones [2].Patients were consulting indigenous health practitioners before they sought biomedical help[3] sorather than being curedmanywerebecoming worse or even dying.Reliance of most blacks on indigenous health practitioners and the apparent failure to reduce the number of fatal illnesses has led the government to consider collaboration with the biomedical fraternity,notably by the World Health Organisation (WHO) at the Alma Alta Conference on Primary care in 1978[4].

This paper explores biomedical health practitioners' views regarding the practices and healthcare delivery methods of the African indigenous health practitioners in Mpumalanga Province, South Africa. It is intended to contribute to empowerment of the latterthrough knowledge acquisition, such that their workwill be respectedand properly understood bythe former.

In 2007 theSouth African government passed the Traditional HealthPractitioners Act to close the gap and address a concern surroundingintegration of traditional and modern medicine. Theincorporation of the two disciplines hadan impact on local communities in accessing their rightsas vested in the Constitution[20],however, despite theWHO's recommendation and the Act,marginalisationpersists[5, 6, 7], withconcerns expressed that the biomedical group were being forced to collaborate with their African counterparts for the sake of reducing the spread of diseases among the community and preventing abandonment of biomedical treatment.Authors [7][2] and [8] have arguedthat integration isthe cornerstone ofany effective health system,essentialto sharing views regarding the care and treatment of diseasesand givingall involveda similar understanding.

${ }^{1}$ Numbers in square parentheses refer to works listed numerically in the bibliography.

DOI: 10.9790/1959-060205101106 $\quad$ www.iosrjournals.org $\quad 101 \mid$ Page




\section{Methods}

The researcher used purposive sampling to select knowledgeable participants about the phenomenon to include in the research project [9], and ones able to share their views regarding practices and healthcare delivery methods followingtheTraditional Health practitioners Act of 2007 (Act no. 22 of 2007). Permission to conduct the study was requested from the sister in-charge (manager) of the selected hospital. Based on agreement and permission being granted to conduct the research in the facility the registered and enrolled nurses were requested to participate, with reasons for the study explained and consent obtained for the individual interviews. Formal appointmentswithdate, time and secure venue for the interview were made. A total of 10 femalesparticipated,(eight registered and two enrolled nurses), but no males. One male registered nurse did not participate because he was on night duty and the two male doctors were taking ward rounds. Interviews were conducted in the month of April 2014 and participationwasvoluntary.

The setting encompassed physical, social and cultural contexts, namely the geographical area of the selected district of Mpumalanga province. Data was collected at the workplace of the participants, which was the office and ward.Aqualitative research design was used to collect data,including participant observation [10] and structured in-depth, individual interviews conducted in English. A voice-recorder was used withthe participants' permission and field notes taken.Data saturation was reached with the tenth participant.

\section{Data analysis}

Voice-recorded data wastranscribed verbatim and notes carefully read and checked by the researcher as she conducted the interviews. Organisation, reduction and giving meaning to data followedTesch's method, as described by[11].

\section{Ethical considerations}

The Ethics Committee of the University of Pretoria provided approval and permission to conduct the study was obtained from the Mpumalanga Provincial Department of Health and at the District department. Consent was also obtained from the participants prior to their participation after being informed about the purpose of the study and its methodology,includingclarification when requested [12]. The participants were informed that participation was voluntary and that confidentiality would be ensured [13].They were free to withdraw from an interview at any time without penalty. The researcher made every effort to protect participants from discomfort and harm, whether physical, emotional, spiritual, economic, social or legal [10].Permission was obtained from themto voice-record the interviews, which lasted from 30 to 45 minutes.

\section{Trustworthiness}

Trustworthiness measures the truth value of a study and is indexed by measures to enhance credibility, dependability and conformability. Credibility was achieved through prolonged engagement with the participants and establishing rapport. Dependability was ensured by the voice-recorder and the transcripts which were available for the use of verification if necessary. Confirmability was ensured by conducting individual interviews until data saturation was attained and taking of field notes by the researcher during the interviews, the voice-recordings of the proceedings during the individual interviews and the verbatim transcripts.

\section{Findings}

\subsection{Demographic characteristics of the biomedical health practitioners}

Of the 10 biomedical health practitioners, the eightregistered andtwoenrolled nurses were interviewed individually. They were all female and their ages ranged between 35 and60.Findings arediscussed per participant.

Table 1: Age of the participants

\begin{tabular}{|l|l|l|l|}
\hline Age group & Frequency & Percentage & Cumulative Percentage \\
\hline $35-40$ & 1 & $10 \%$ & $10 \%$ \\
\hline $40-45$ & 3 & $30 \%$ & $40 \%$ \\
\hline $45-50$ & 1 & $10 \%$ & $50 \%$ \\
\hline $50-55$ & 3 & $30 \%$ & $80 \%$ \\
\hline $50-60$ & 1 & $10 \%$ & $90 \%$ \\
\hline $55-60$ & 1 & $10 \%$ & $100 \%$ \\
\hline Total & 10 & $100 \%$ & \\
\hline
\end{tabular}


Biomedical health practitioners' views regarding the practices and health care delivery methods ....

\subsection{Themes and Sub-themes}

Two main themes and sub-themes were identified which give clear views of the biomedical health practitioners regarding the practices and healthcare delivery methods of the African indigenous health practitioners in Mpumalanga province.

Table 3: The themes and sub-themes

\begin{tabular}{|c|c|}
\hline Themes & Sub-themes \\
\hline $\begin{array}{l}\text { 1.Unacceptance of the } \\
\text { African indigenous health } \\
\text { practitioners'practices and } \\
\text { healthcare delivery methods } \\
\text { by the biomedical health } \\
\text { practitioners }\end{array}$ & $\begin{array}{l}\text { 1. Strong unmeasured } \\
\text { African medicine } \\
\text { 2. Unhygienic conditions } \\
\text { 3. Defaulting of treatment } \\
\text { 4.Delays in referral }\end{array}$ \\
\hline $\begin{array}{l}\text { 2. Group interaction was } \\
\text { suggested between these } \\
\text { two types of health } \\
\text { practitioner to enhance } \\
\text { understanding }\end{array}$ & $\begin{array}{l}\text { 1 Health education } \\
\text { 2. Changing mind-set } \\
\text { 3.Understanding each } \\
\text { other's sector } \\
\text { 4.Communication } \\
\text { 5.Research regarding } \\
\text { traditional medicine }\end{array}$ \\
\hline
\end{tabular}

6.2.1 Theme One: Unacceptance of the African indigenous health practitioners' practices and healthcare delivery methods by the biomedical health practitioners

Biomedical health practitioners expressedtheir feelings regarding the practices and healthcare delivery methods by the African indigenous health practitioners. They indicated that their negative attitudes had developed when the latter delayed referring patients to hospital, giving strong unmeasured medicine and the patients defaulting to biomedical treatment focusing on indigenous medicine.

The sub-themes identified are outlined as follows:

\subsubsection{Sub-theme One: Strong unmeasured African medicine}

Some of the biomedical health practitioners were reluctant to collaborate with the African indigenous health practitioners in the belief that they were illiterate and used unscientific methods, giving strong unmeasured indigenous medicine to the patients which resulted in damaging theirinternal organs, suchas theliver. However, some acknowledged the establishment of the Act and were ready to work with them,albeitabarrier identified in that the African indigenous health practitioners lacked policies to cover their practices [21].

\subsubsection{Sub-theme Two: Unhygienic conditions}

Biomedical health practitioners were labelling African indigenous health practitioners as having poor hygienic standards,not bathing, washing their hands orworkingincleanenvironments: "You know what, to me, I was amazed, in fact most of our traditional healers are not aware of the hygiene. Their patients do not bath while here at the hospital we bath them. You find that their medicine stay for a long time until it has that mould on top but they still give patients to drink. They use one razor blade to every patient coming to them, I suggest that the department can check one traditional healer if is doing correct."

\subsubsection{Sub-theme Three: Defaulting of treatment}

Biomedical health practitioners were concerned about the default of the treatment by patients after discharge from the hospital, as they returned to the African indigenous health practitioners to start from where they hadleft offwith the indigenous medicine. This attitude put more communities at risk of contracting and spreading infectious diseases, and even death: "In Mpumalanga, aa---h, people believe in traditional healers which is really disturbing because patients default treatment. I suggest if we can find a facility where we can keep the patients until they complete their treatment after discharge'.

\subsubsection{Sub-theme Four: Delays in referring patients to the clinic or hospital}

Biomedical health practitioners were concerned about the delay of referring patients to them, indicating that African indigenous health practitioners referred patients only when they had failed and a patient's condition was at an advanced stage.

\subsubsection{ThemeTwo: Group interaction between types of health practitioner to enhance understanding}

Biomedical health practitioners were availing themselves to meettheir African counterpartsat workshops and run an awareness campaign to share ideas, understand different types of conditions and how they 
weremanaged for the improvement of service delivery. Theyadded that the outcome of their meetings reduced risky practices and there would be a great improvement in referring patients to them. Their integration was seen as central to effective collaboration.

\subsubsection{Sub-theme one: Health education}

Biomedical health practitioners indicated that they werewilling to providehealth education regarding the different types of disease. They also showed willingness to meet during the workshops in order to empower the indigenous practitioners with knowledge that wouldenable them to handle patients with confidence. Such teaching could enable both groups to understand and appreciate each other's contributionstothe provision of service for the benefit of the patients. Biomedical health practitioners felt honoured and superior to be facilitators of health education: "Let the traditional healers come together with the medical staff to talk about diseases." "Here at Mpumalanga they decided to call the sangomas in workshop to give them health education aboutdiseases."

Biomedical health practitioners considered the establishment of the Traditional Health Act as the foundation for discussing their meetings: "At least they are recognised now with their Act." "First we have to teach the African indigenous health practitioners, explain side effects of traditional medicine to patients, they should understand before treating them. The doctors explained to them why patients are not healing. We educate thefamilies the danger of herbal treatment so that if the patient is discharged they must not take patient to herbalist."

The acceptance of the Traditional healers Act by the biomedical health practitioners brought good collaboration between both practitioners and demonstrated a success in reducing the risks of the African indigenous health practitioners' practices to patients [14].

\subsubsection{Sub-theme two: Changing mind-set}

Meetings, workshops, awareness and health education would change negative ways of thinking about the African counterparts and improve attitudes towards them. Theywould promote trust and respect between the two groups, so that they could work together to reach their common goal. Each practitioner's role must be clear in handling the patient with different conditions to prevent conflict and promote good mutual relationships.

\subsubsection{Sub-themeThree:Understanding each other's sector}

Biomedical health practitioners accepted African indigenous health practitioners on conditions that would make them understand each other regarding service delivery. They felt they should be able to work together, understand each other's strength and weaknesses and learn from each other. The two-way communication would reduce mistrust and disrespect because they wouldbe able to share ideas about the referral and prognosis of their patients'conditions.

Biomedical health practitioners accepted that they werefewer in numberwith less accessibility and highercosts [17]. Anoption wasto engage themselves for the benefit of the patients and the smooth running of the service.

\subsubsection{Sub-theme four: Communication}

Three participants indicated that communication wasbehind the success of every action taken to move forward: "Good personal relationship between the two health care practitioners is to have communication line. African indigenous health practitioners must not feel inferior because they are not educated. They must know that they are doing quality nursing care." "We must make sure if our patients are discharged from the facility we must visit, phone them about the treatment outcome. "'Hmm! They must be educated on how these patients should be nursed. They should have protective clothing like mask. They should refer sick patients immediately."

\subsubsection{Sub-theme five: Research regarding traditional medicine}

Participants felt that in order to sustain relationships, collaboration and trust research shouldbe conductedon the site of African indigenous medicine, thus to see its efficacy and safety: "Hmm! hey! Research should be done to this traditional medicine and come out with one medicine that can really help. Traditional healers can say we are using this, let the research or laboratory tests be done to see if it kills bacteria."

\section{Discussion}

It has been determined that biomedical health practitioners were unlikely to collaborate with the African indigenous health practitionerswithout the Act. The latter were happy that they wouldwork together but the negative attitude of the former was a hindrance,withno interaction between them.Rather, there wasa perception that they were mistrusted and looked down upon. 
A model for convergence and engagement between these two health groupsis imperative, considering the disease burden challenging the Mpumalanga province, and this would facilitate integration, trust, relationships, capacity and changing ofnegative attitudes.

The African indigenous health practitioners were seen as unhygienic by the biomedical health practitioners. This confirmed the view of [7] onthe issue of untidiness, such as unscientific methods of traditional medicine, lack of hand washing, non-sterile equipment, and lack of measured prescription of traditional medicine according to age and weight of the patient. Patients consulting the African indigenous health practitioners resulted in complications such as diarrhoea, dehydration, poisoning and sores on the body. According to [16], meeting between the different practitioners could empower each with the requisite knowledge regarding the care of patients with a variety ofdiseases and patients would be saved from complications.

According to [15], most biomedical health practitioners saw an advantage inintegration as African indigenous health practitioners were preferred by the community and it wouldhelpthem access the community and strengthen their referral system.

Participants demonstrated their willingness to work with African indigenous health practitioners in order to understand each other's strengths and weaknesses and to learn from each other, thus empowering the latter with knowledge to enhance provision of quality care to patients as well as adherence to treatment. According to [7], mutual understanding between biomedical health and the African indigenous health practitioners was viewed as central and crucial to effective collaboration. To increase acceptance and understanding of their capabilities between thetwo types, participants indicated that they would meet together to resolvedifferences for the smooth running of the service.

According to [18], tension between biomedical health and African indigenous health practitioners isfuelled by lack of trust and mutual understanding. The two health practitioners had significant differences in their world view because of lack of compromise. It is clear that communication and respect between these two practitioners could take them to a better level of engagement.[18] also suggestedthat integration would eliminate fear and mistrust, and allow for continuity of health care.

As argued by [19], research is needed to document the nature, value and effectiveness of African indigenous medicine, important in initiating collaboration with the biomedical counterparts. For the former to have a clear understanding ofthe use of their indigenous medicine, research should be conductedbefore they use it. It should be sent for laboratory tests to establish its safety before it is used. Patients should be tested before and after the treatment, and the impact and outcome of treatment determined by comparison of pre- and posttreatment results [14].

\section{Conclusions}

Through the meetings, workshops, health education and awareness campaigns held by the biomedical health and African indigenous health practitioners, it was agreed that practices and healthcare delivery methods were to be improved. Trust and relationshipswerebuilt and negative attitudeschallenged. The research reported in this article has provided an insight into the needs of collaboration between biomedical and African indigenous health practitioners in the field of health for the sake of saving the community from harmful practices. Furthermore, it should contribute to anunderstanding of sharing knowledge for the benefit of both patients and health practitioners and the development of a model for convergence and engagement to sustain their relationship throughout. Continuous in-service education is imperative to gain more knowledge and skills that will enable them to make intervention when necessary.

The study found that biomedical health practitioners have the same goal astheir African counterparts, namely that of healing patients.However, there is a need to modify the practices and healthcare delivery methods through health education, workshops and awareness campaign thatcan empower each other with knowledge. The former were compelled to collaborate with the latter, when considering the realities of staff shortages, cultural values and norms and disease burden challenging the Mpumalanga province.

\section{Acknowledgement}

The author would like toexpress her gratitude to the UNEDSA for financial support to this research and Mpumalanga Province for granting her permission to conduct the study.

\section{References}

[1]. T. Joy, Side Effects of All National Chinese Herbal Medicine. Livestrong.com, 2015.

[2]. M.G. Mokgobi,Views on traditional healing: Implications for integration of traditional healing and western medicine in South Africa,2012.

[3]. B. Hlabano,Perceptions of traditional healers on collaborating with biomedical health professionals in uMkhanyakude district of KwaZulu-Natal, 2013.

[4]. World Health Organization, Report of the International Conference on Primary Health Care, Geneva, 1978. 
[5]. HRPULSE, Traditional Healer Certificates-Validor Invalid.Labournet,support@labournet.com, 2014.

[6]. N. Mbatha,R.A.Street, M. Ngcobo,N. Gqaleni, Sick certificates issued by South African traditional health practitioners: Current legislation, challenges and the way forward, Afr Med J,102, 2016:129-131

[7]. D.VanRooyen, B. Pretorius, N.M.Tembani, W.Ten Ham, Allopathic and Traditional Health Practitioners 'collaboration, Curationis 38 (2), Hart. \#2015: 1495

[8]. 8.K.A.Viney, P.Johnson, M. Tagaro, S. Fanai, N.N. Linh, P. Kelly, D. Harley,A.Sleigh, Tuberculosis patients 'knowledge and beliefs about tuberculosis: a mixed methods study from the Pacific Island nation of Vanuatu, $B M C$ Public Health, 14,2014:467.

[9]. N.Burns, S.K Grove,The Practice of Nursing Research (Philadelphia, Saunders, 2005).

[10]. K. Parahoo,Nursing Research principles, process and Issues (McMillan. 2006)

[11]. A.S. De Vos, Research at Grassroots- a Primer for the caring profession(Pretoria, Van Schaik, 1998)

[12]. N.Burns, S.K. Grove,The practice of Nursing Research (St Louis, Philadelphia, Saunders Elsevier,2009)

[13]. J.H. McMillan, S.Schumacher, Research in Education. EvidenceBased inquiry,2010: 338-339.

[14]. K. Busia, O.M.J. Kasilo, Collaboration between traditional health practitioners and conventional health practitioners: Some country experiences. West African Health Organisation. WHO Regional Office for Africa, 2010.

[15]. N. Mngqundaniso, K. Peltzer, Traditional Healers and Nurses: A qualitative study on their role on sexually transmitted infectious including HIV and AIDS in Kwazulu-Natal, South Africa,Afr J Tradit Complement Altern Med, 5(4), 2008:380-386.

[16]. M.G. Matsabisa, T. Spotose, D. Hoho, M. Javu , Traditional health practitioners 'awareness training programme on TB, HIV and AIDS: a pilot project for the Khayelitshaarea in Cape Town, South Africa,Journal of Medical Plants Research Vol.3 (3), 2009:142-147.

[17]. A.Wamba, D. Groleau, Constructing Collaborative Processes between Traditional, Religious, and Biomedical Health Practitioners in Cameroon. Nordic Journal of African Studies 21(2) 2012:49-74.

[18]. C. Kangwa, R. Catron, Traditional Healing and Western Medicine: Segregation or Integration? 2010.

[19]. USAID, Collaborating with traditional healers for HIV prevention and care in Sub-Saharan Africa: Africa: Suggestions for programme managers and field workers, 2006.

[20]. S.S. Latif. Integration of African Traditional Health Practitioneand medicine into the Health Care Management System in the province of Limpopo, 2010:2.

[21]. 21.S.M. Nemutandani, S.J. Hendricks, F.M. Mulaudzi, Perceptionsand experiences of allopathic health practitioners on collaboration with traditional health practitioners in post-apartheidSouth Africa, 2016:2. 